\title{
APLICAÇÃO DE SISTEMÁTICA DE SOLUÇÃO DE PROBLEMAS PARA AUMENTO DE PRODUTIVIDADE DE UMA EMPRESA NO RAMO VIÁRIO
}

\author{
Juliana Souza Gonçalves (UNESA) juliana_souza3@ hotmail.com \\ Nathalia Martinho Vidal (UNESA) nvidal.rj@gmail.com \\ Alexandre Camacho da Paixão (UNESA) profalexandrepaixao@gmail.com \\ Marcone Freitas dos Reis (UNESA) marconefreis11@gmail.com
}

\section{Resumo}

Uma das grandes necessidades das empresas atualmente é o estabelecimento de uma sistemática que permita a melhoria contínua dos processos, aumentando a produtividade, gerando redução de custos, e mantendo-se competitiva no mercado globalizado. A busca contínua pela qualidade tem levado as organizações à implementação de processos cada vez mais burocráticos, onde faz-se necessário o emprego de muitas horas de trabalho na conferência de inúmeros relatórios que, muitas das vezes não são tão úteis a ponto de justificarem o esforço empregado. A gestão por processos auxilia nesse aspecto, pois fornece insumos para gerenciar o desempenho dos processos de forma inteligente, evitando retrabalhos e processos que não irão agregar valor ao fluxo produtivo. O presente estudo propõe, portanto, uma análise do setor de manutenção de equipamentos de uma empresa de grande porte do ramo de operação viária na cidade do Rio de Janeiro, com o objetivo de aumentar a produtividade nos processos administrativos e, assim, reduzir os desperdícios.

Palavras-Chaves: Melhoria Contínua; Produtividade; Ramo Viário.

\section{Introdução}

As organizações são desafiadas diariamente em suas operações, no mundo atual, onde o cenário do mercado tornou-se altamente dinâmico e competitivo, exigindo que as organizações formulem condições de processos que melhor se adequem aos seus produtos e serviços para manterem-se nesse cenário em constante mudança, com prioridades e mutações, surge a necessidade de criar estratégias para se manter inovadora.

Os gestores estão reaprendendo novos modos de gerir, e os trabalhadores estão buscando contribuir, com seus conhecimentos, para melhoraria dos processos.

Os clientes e consumidores estão cada vez mais exigentes, querendo produtos com mais qualidade e com preço competitivo. Com isso as organizações estão com foco na qualidade de 
seus produtos e/ou serviços, através da melhoria contínua de como o trabalho é feito, com menor custo e mais eficiência na utilização dos recursos disponíveis.

Para Slack (2009), é necessário ter qualidade dentro da operação, detectar desperdícios, e saber implementar ferramentas da qualidade para diminuir gargalos, quanto menos erros em cada processo da operação, menos tempo será necessário para a correção e consequentemente, menos confusão e irritação.

Segundo Paim et al. (2009), os processos estão intrinsicamente relacionados aos fluxos de objetos na organização, sejam eles objetos materiais, informações, capital, conhecimento, ideias ou qualquer outro objeto que demande coordenação de seu fluxo. Aos processos cabe o desenvolvimento ou desenrolar dos fluxos de objetos enquanto as funções ou unidades organizacionais atribui se a concentração de conhecimentos por semelhança.

Os processos são objetos de controle e melhoria, mas também permitem que a organização os utilize como base de registro do aprendizado sobre como atuar, atuou ou atuara em seu ambiente ou contexto organizacional.

Diante da necessidade de identificar e tratar desperdícios, o objetivo deste estudo é analisar os processos do setor de manutenção de equipamentos de uma empresa de grande porte do ramo de operação viária na cidade do Rio de Janeiro.

\section{Fundamentação Teórica}

A fundamentação teórica se baseia na revisão de livros, artigos, dissertações e teses, cujo tema tenha relevância para este estudo com a finalidade de dar embasamento teórico para essa pesquisa voltada para a sistemática de solução de problemas.

\subsection{Estrela Decisória}

Para Macieira e Maranhão (2004, apud GONÇALVES, 2011, p. 253), a estrela decisória é uma ferramenta da qualidade que pode ser vista como um método gerencial do ciclo PDCA, tendo em vista que ela auxilia na tomada de decisão em diferentes etapas de projetos.

Ainda segundo Macieira e Maranhão (2004, p.148, apud GRECO, 2005, p. 25), esta ferramenta é proveniente do Japão e ganhou popularidade, no Brasil, com os Círculos de Controle da Qualidade - CCQ. Para Gonçalves (2014), a estrela decisória consiste na 
combinação de diversas ferramentas da qualidade, com o objetivo de resolver um determinado problema. Para isso, é necessário que sejam seguidos 8 passos, conforme a seguir:

- Passo 1: Especificar o problema e definir objetivos.

- Passo 2: Selecionar fatores e coletar dados.

- Passo 3: Organizar e analisar dados.

- Passo 4: Estabelecer as causas.

- Passo 5: Elaborar soluções.

- Passo 6: Avaliar as soluções.

- Passo 7: Decidir entre as soluções.

- Passo 8: Implementar as soluções escolhidas.

Ao final da implantação da estrela decisória, o ciclo PDCA estará completo, o qual consiste em Planejar, Executar, Checar e Agir.

A estrela decisória para Maranhão (2004), nada mais é que uma escada de oito degraus, onde cada um é pré-requisito para chegada no seguinte, possibilitando assim, o atingimento do objetivo final: a resolução do problema proposto.

\subsection{Gráfico de Pareto}

Segundo Paladini (2009), Vilfredo Pareto desenvolveu um estudo sobre a distribuição de renda do seu país, onde constatou que $80 \%$ da riqueza ficava com uma pequena parte da população, que correspondia a $20 \%$. Essa constatação foi demonstrada através de um gráfico, que ficou conhecido como gráfico de Pareto, e se tornou uma das mais conhecidas ferramentas qualidade.

Para Seleme (2012), o gráfico de Pareto foi desenvolvido por Joseph Juran a partir dos estudos de Vilfredo Pareto e Max Otto Lorenz. Segundo o autor, Juran estabeleceu uma classificação dos problemas de qualidade, dividindo-os em poucos vitais e muitos triviais, ou seja, a maior quantidade dos defeitos se refere a poucas causas. 


\subsection{Tempo de Ciclo}

O tempo de ciclo (TC), segundo Gonçalves (2014), é constituído pelo tempo que decorre entre cada execução de um processo e suas atividades.

Para Tálamo (2016), tempo de ciclo pode ser definido como o tempo existente entre a saída de um produto e a saída de um imediatamente subsequente.

De acordo com Werkema (2012), a análise do tempo de ciclo pode ser usada para avaliar o tempo gasto na produção de um bem ou serviço. Para a autora, o tempo de ciclo é determinado cronometrando-se o tempo de processamento, de movimentação de material e de fila. Dessa forma, é possível identificar e mensurar os atrasos na produção.

\subsection{Matriz de Priorização}

A matriz de priorização, segundo Zabaleta (2002), é uma ferramenta para estabelecer prioridades, de acordo com diferentes critérios, que podem ser por preferências simples, como atividades que agregam valor x esforço empregado necessário para a resolução da tarefa.

Para Seleme (2012), a matriz permite um direcionamento adequado de recursos, fazendo com que a organização potencialize a solução a ser estabelecida.

De acordo com Werkema (2012), a matriz de priorização consiste em atribuir pesos para correlacionar as principais causas potenciais com o problema considerado.

Conforme pode ser observado na Figura 1 a seguir, as atividades que se encontram no quadrante "I" da matriz devem ser priorizadas, pois são propostas com alto valor agregado e necessitam de baixo esforço empregado.

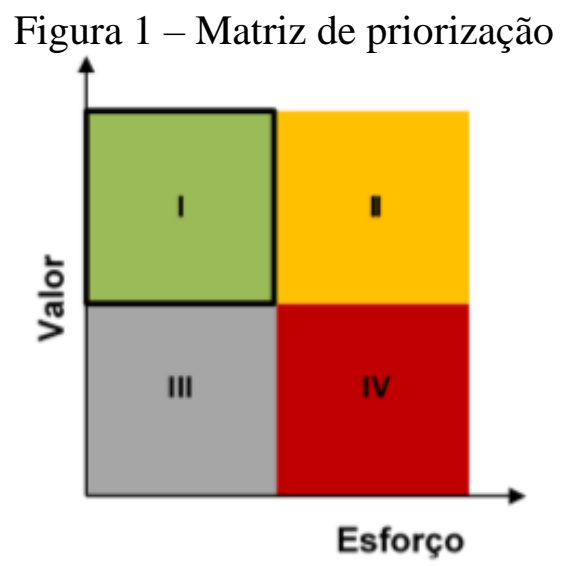

Fonte: Werkema (2012) 
As atividades do quadrante "II" são as atividades que geram alto valor ao processo produtivo, porém que demandam maior esforço para sua implementação. Devido ao alto nível de esforço necessário, é preciso uma avaliação criteriosa para decidir se vale a pena executá-las.

As atividades do terceiro quadrante devem ser executadas dentro da possibilidade de tempo, devido ao baixo valor agregado.

Já as atividades do quadrante "IV", podem ser adiadas ou até mesmo extintas. São as atividades que não justificam o esforço empregado.

\subsection{Tecnologia da Informação}

A Tecnologia da Informação, segundo Belmiro (2015), "é uma das muitas ferramentas que os gerentes usam para solucionar problemas." Para o autor, os sistemas de informação são fundamentais para a sobrevivência de uma empresa, de modo que seu elemento principal é justamente a informação, seu armazenamento e tratamento. Dentre os principais softwares utilizados, pode-se destacar o Bizagi e o Google Forms, que serão utilizados neste estudo.

De acordo com o site oficial do Bizagi, o Bizagi Process Modeler é uma ferramenta potencial para modelagem e criação de processos que permite desenhar, diagramar, documentar e publicar os processos utilizando o padrão BPMN (Business Process Model and Notation).

O Google Forms, também conhecido como Formulários Google, conforme o site oficial da empresa homônima, é uma ferramenta que permite a criação de formulários personalizados para pesquisas e questionários, sem qualquer custo adicional. Além disso, os dados coletados com o Google Forms podem ser acessados online e analisados em tempo real, permitindo ao usuário obter uma visão gerencial e criar gráficos.

\section{Metodologia}

A metodologia empregada neste estudo consiste em um levantamento bibliográfico em livros, artigos, documentos fornecidos pela empresa, entrevistas com profissionais da empresa objeto de estudo e observações dos processos com o objetivo de coletar informações.

Para o desenvolvimento da metodologia, foram aplicadas as técnicas: estrela decisória, matriz de priorização (esforço empregado na execução da tarefa $\mathrm{x}$ benefício gerado), entre outras ferramentas para alcançar o objetivo proposto. 
A empresa forneceu um total de 746 formulários de inspeção rotineira acumulados na mesa do operador. Foram utilizados como referência os dados priorizados dos documentos com maior índice de incidência, totalizando 615 unidades, com periodicidade mensal, bimestral e semestral, no período de março a agosto de 2019.

Foi utilizado o Microsoft Excel para tratamento dos dados, elaboração dos gráficos, análise do quantitativo e elaboração do gráfico de Pareto.

\section{Estudo de Caso}

\subsection{Cenário de Atuação da Empresa}

O objeto de estudo deste trabalho trata-se da maior parceria público privada do país, uma empresa responsável pelo projeto que engloba a construção e concessão de operação de dois túneis. Dentre os diversos setores e campos de aplicação da empresa, o setor de manutenção de equipamentos é responsável por garantir que todos os dispositivos dos túneis desempenhem as suas funções corretamente, executando as manutenções preditivas, corretivas e preventivas. Para isso, são preenchidos os FIR (Formulários de Inspeção Rotineira) que têm periodicidades variadas, de acordo com o tipo de manutenção e equipamento que será inspecionado.

\subsection{Análise do Processo de Cadastro de FIR (Formulários de Inspeção Rotineira)}

Foi realizado o mapeamento do processo de cadastro de FIR, utilizando a notação BPMN para melhor visualização e entendimento do processo atual (As Is). Conforme pode-se observar na Figura 2 a seguir. 
Figura 2: Mapeamento do processo de cadastro de FIR, fase atual (As Is)

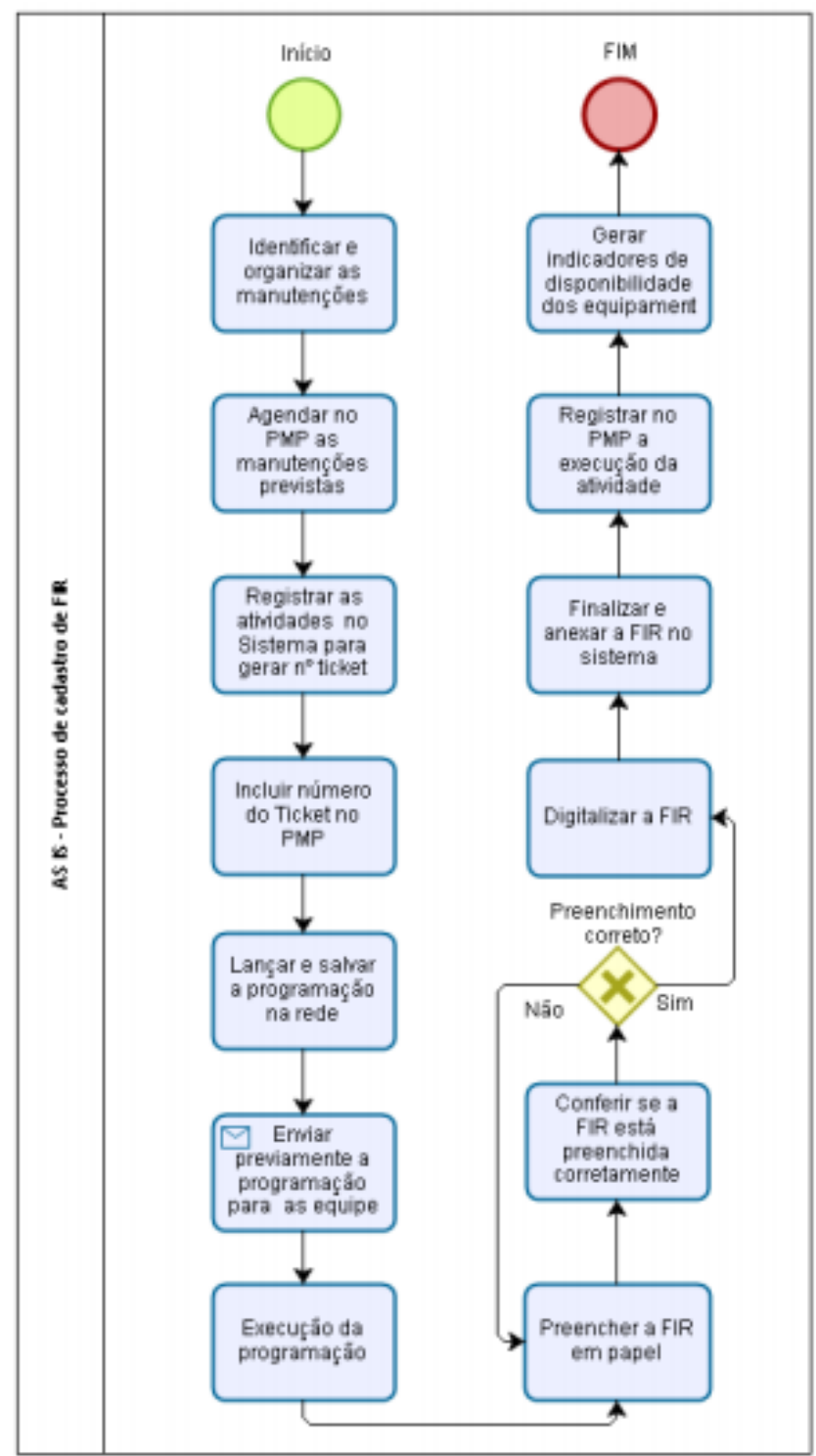

Fonte: Autores (2019)

Conforme pode-se observar, o processo de lançamento de FIR no sistema de gestão consiste em um trabalho manual e moroso, e muitas das vezes os documentos acabam se acumulando na mesa do operador.

\subsection{Aplicação da Estrela Decisória}

A estrela decisória foi utilizada para definir quais ferramentas seriam utilizadas em cada etapa do estudo. Para isso, foi elaborado um planejamento e o estudo foi dividido em 8 etapas, conforme apresentado no Quadro 1 a seguir. 


\begin{tabular}{|c|l|}
\multicolumn{2}{|c|}{ Quadro 1 - Etapas do estudo } \\
\hline Passo & \multicolumn{1}{c|}{ Etapas } \\
\hline 1 & Especificar o problema e definir objetivos \\
\hline 2 & Selecionar fatores e coletar dados \\
\hline 3 & Organizar e analisar dados \\
\hline 4 & Estabelecer as causas \\
\hline 5 & Elaborar soluções \\
\hline 6 & Avaliar as solucões \\
\hline 7 & Decidir entre as soluções \\
\hline 8 & Implementar soluções escolhidas \\
\hline
\end{tabular}

Fonte: Autores (2019)

Em seguida, as informações foram dispostas conforme o Quadro 2 a seguir, de forma que fosse possível demarcar em que etapa cada ferramenta seria melhor empregada, a fim de cumprir com os objetivos deste estudo.

Quadro 2 - Passos da estrela decisória

\begin{tabular}{|c|c|c|c|c|c|c|c|c|}
\hline \multirow{2}{*}{ Ferramenta } & \multicolumn{7}{c|}{ Passos da Estrela Decisória } \\
\cline { 2 - 10 } Estrela Decisória & $\mathrm{x}$ & $\mathrm{x}$ & & & $\mathrm{x}$ & $\mathrm{x}$ & & \\
\hline $\begin{array}{c}\text { Matriz de } \\
\text { Priorização }\end{array}$ & & & $\mathrm{x}$ & $\mathrm{x}$ & & & $\mathrm{x}$ & $\mathrm{x}$ \\
\hline Gráfico de Pareto & & $\mathrm{x}$ & $\mathrm{x}$ & $\mathrm{x}$ & $\mathrm{x}$ & & $\mathrm{x}$ & $\mathrm{x}$ \\
\hline $\begin{array}{c}\text { Análise do } \\
\text { Tempo de Ciclo }\end{array}$ & & $\mathrm{x}$ & & & & & \\
\hline Fluxograma & & $\mathrm{x}$ & $\mathrm{x}$ & & & & & $\mathrm{x}$ \\
\hline
\end{tabular}

Fonte: Autores (2019)

Dessa forma, foi possível decidir quais métodos seriam necessários utilizar em cada etapa do projeto, permitindo o direcionamento eficaz dos esforços e gerando resultados mais concretos em cada etapa.

\subsection{Gráfico de Pareto}

Para melhor avaliação do problema, foram coletados os dados referentes aos documentos acumulados na mesa do operador. Para cada tipo de formulário de inspeção rotineira, foram contabilizados e dispostos na Tabela 1 a seguir, para serem analisados. 
Tabela 1 - Percentual acumulado

\begin{tabular}{|c|c|c|c|}
\hline Periodicidade & Frequência & Frequência Acumulada & Percentual Acumulado \\
\hline Mensal & 367 & 367 & 49,2 \\
\hline Bimestral & 152 & 519 & 69,6 \\
\hline Semestral & 96 & 615 & 82,4 \\
\hline Trimestral & 86 & 701 & 94,0 \\
\hline Semanal & 38 & 739 & 99,1 \\
\hline Quinzenal & 5 & 744 & 99,7 \\
\hline Anual & 2 & 746 & 100 \\
\hline Total Geral & 746 & & \\
\hline
\end{tabular}

Fonte: Autores (2019)

Tendo em vista que a mão-de-obra é um recurso escasso e visando o melhor uso de recursos, utilizamos o gráfico de Pareto conforme apresentado na Figura 3 a seguir, a fim de identificar os problemas mais relevantes e concentrar os esforços nas principais causas do acúmulo de pendências.

Figura 3 - Gráfico de Pareto com as principais causas identificadas

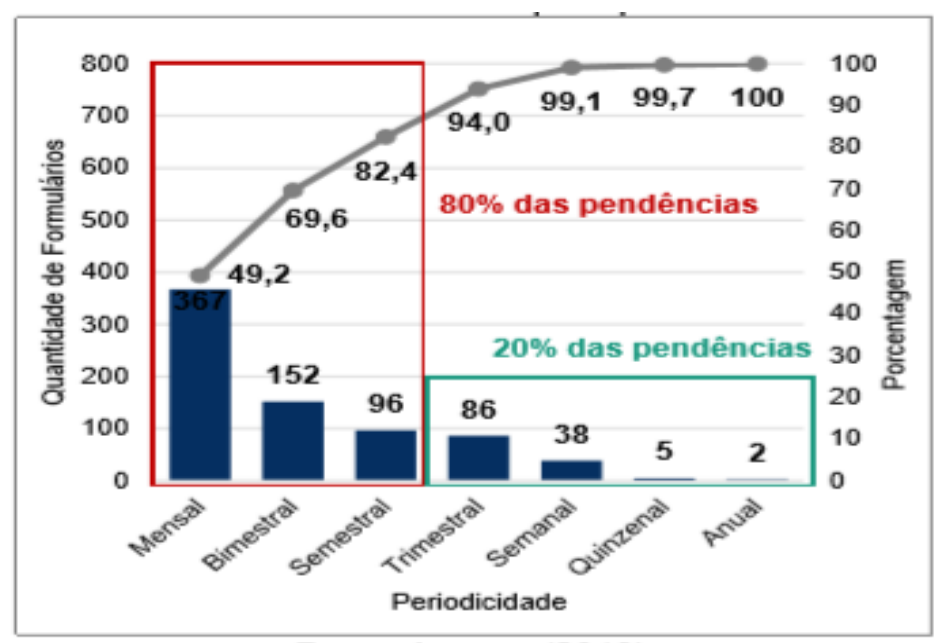

Fonte: Autores (2019)

Assim, tendo em vista o resultado do gráfico de Pareto, determinou que o plano de ação seria agir prioritariamente nos processos relacionados aos formulários de inspeção rotineira com periodicidade mensal, bimestral e semestral.

\subsection{Análise do Tempo de Ciclo}

Aplicando-se o método de Werkema e utilizando um cronômetro, papel e caneta, foram observadas e mensuradas em horas a duração total que compreende a atividade de lançamento 
de um formulário de inspeção rotineira. Para o estudo, foi utilizada uma amostra da FIR 9.1 Remotas Geral que tem periodicidade bimestral e a atividade foi desmembrada em 4 etapas: abertura de ticket, inclusão de ticket no PMP, lançamento de atividade na programação diária e lançamento de FIR. O resultado foi disposto na Tabela 2 a seguir:

Tabela 2 - Duração em horas de cada etapa da atividade

\begin{tabular}{|l|c|}
\multicolumn{1}{c|}{ Atividade } & Tempo (Horas) \\
\hline Abertura de ticket & $00: 02: 39$ \\
\hline Inclusão de ticket no PMP & $00: 00: 31$ \\
\hline Lançamento de atividade na programação diária & $00: 02: 51$ \\
\hline Lançamento de FIR & $01: 36: 17$ \\
Duração total da atividade & $01: 42: 18$ \\
\hline
\end{tabular}

Fonte: Autores (2019)

Cabe ressaltar que o tempo de lançamento da FIR é agravado pelas dificuldades de infraestrutura, já que, durante o lançamento de FIR é necessária a digitalização do documento preenchido e esta etapa durou aproximadamente 58 minutos, devido às falhas na impressora disponível no setor. De acordo com um funcionário do setor, essas falhas são comuns e fazem parte do cotidiano, tornando o trabalho moroso e maçante. Além disso, a impressora mais próxima fica em torno de 15 metros de distância da mesa do operador e, quando falha, o operador precisa se deslocar até outro setor, uma distância de aproximadamente 30 metros.

Outro ponto importante a se destacar é que a impressora mais distante é de uso comum e muitas das vezes está sendo utilizada por outros funcionários. Assim, é preciso aguardar na fila, o que eleva o tempo de duração da atividade. A solução proposta para diminuir consideravelmente o tempo de ciclo foi a substituição da FIR impressa pela FIR digital utilizando o Google Forms. Dessa forma, o tempo de ciclo reduziu consideravelmente, de $1 \mathrm{~h}$ 42 min para 53 min, conforme pode ser observado na Tabela 3 a seguir.

Tabela 3 - Duração em horas de cada etapa da atividade

\begin{tabular}{|l|c|}
\hline \multicolumn{1}{|c|}{ Atividade } & Tempo (Horas) \\
\hline Abertura de ticket & $00: 02: 39$ \\
\hline Inclusão de ticket no PMP & $00: 00: 31$ \\
\hline Lançamento de atividade na programação diária & $00: 02: 51$ \\
\hline Lançamento de FIR & $00: 47: 24$ \\
\hline Duração total da atividade & $00: 53: 25$ \\
\hline
\end{tabular}

Fonte: Autores (2019) 
Na Figura 4 a seguir, é possível observar que as mudanças efetuadas vão impactar apenas no tempo de lançamento de FIR, tendo em vista que os tempos de abertura de ticket, inclusão de ticket no PMP e lançamento de atividade na programação diária já são tarefas ágeis

Figura 4 - Gráfico comparativo

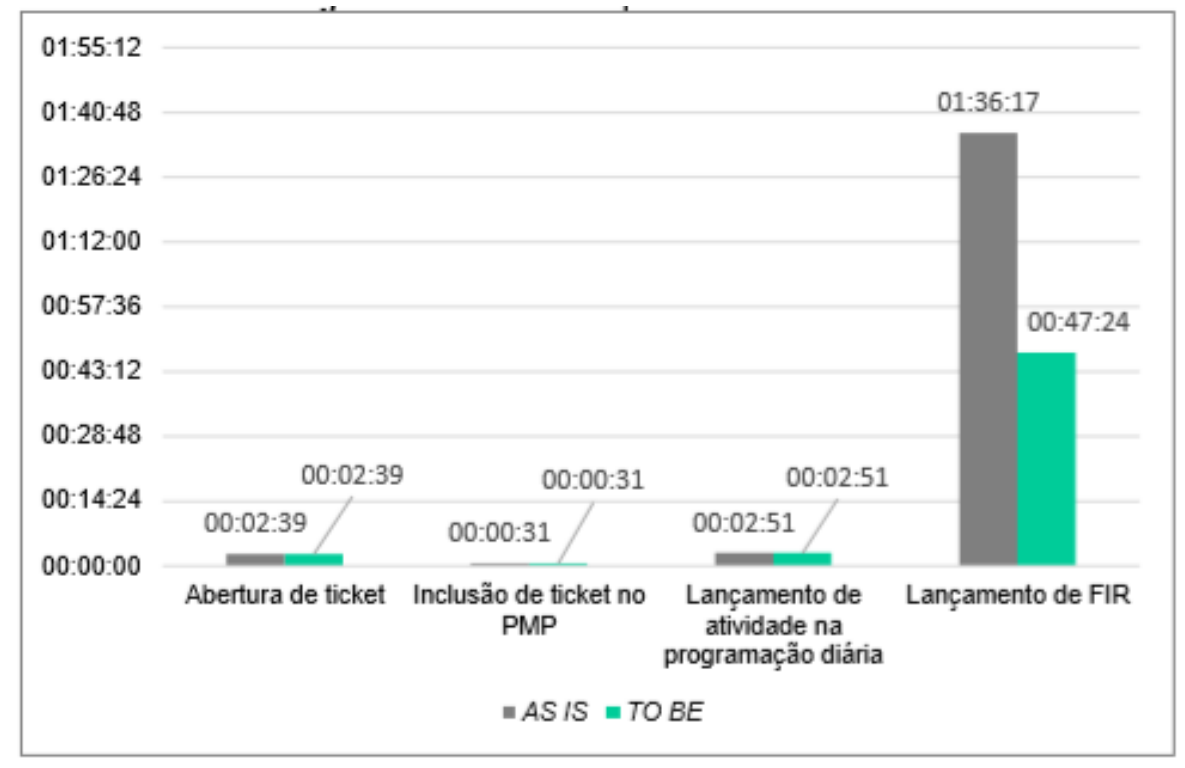

Fonte: Autores (2019)

Apesar disso, o tempo total da atividade reduziu drasticamente, visto que as ações foram direcionadas principalmente à atividade crítica, gerando uma redução de $52 \%$ no tempo total de ciclo. Além disso, pode-se afirmar que, com a substituição, uma quantia considerável de papel poderá ser economizada, tendo em vista que a impressão de FIR equivale a 792 folhas por mês1 no setor em média.

Assim, pode-se afirmar que houve um ganho significativo tanto em produtividade, quanto em material, já que com o método empregado foi possível realizar a mesma atividade investindo menos tempo e dinheiro.

\subsection{Matriz de Priorização}

Para definição das atividades que mais agregam valor na área analisada, foi elaborado um levantamento das principais atividades do setor, e empregado o método da matriz de priorização. A Tabela 4 a seguir, apresenta as atividades. 
Tabela 4 - Descrição das atividades da área analisada

\begin{tabular}{|c|c|}
\hline Atividade & Descriçăo \\
\hline 1 & $\begin{array}{l}\text { Planejamento de atividades de manutençäo preventiva, preditiva e } \\
\text { cometiva das equipes de manutençбes elétrica e mecanica dos dois } \\
\text { tumos (PMP). }\end{array}$ \\
\hline 2 & $\begin{array}{l}\text { Acompanhamento das equipes em atividades criticas (manutençato em } \\
\text { subestaçסes, geradores, bombas de drenagem, entre outros). }\end{array}$ \\
\hline 3 & $\begin{array}{l}\text { Execução de manutençoes mais complexas e que requerem } \\
\text { conhecimento especialzado. }\end{array}$ \\
\hline 4 & Controle de insumos para manutençбes. \\
\hline 5 & Controle do orçamento da área. \\
\hline 6 & $\begin{array}{l}\text { Avaliaçăo dos checklists (FIR) de todas as manutençøes executadas por } \\
\text { todas as equipes. }\end{array}$ \\
\hline 7 & $\begin{array}{l}\text { Lançamento de todas as atividades executadas pelas equipes de } \\
\text { manutençăo no sistema viário. }\end{array}$ \\
\hline 8 & $\begin{array}{l}\text { Elaboraçăa de documentaçăo interna da área (procedimentos } \\
\text { obrigatórios exigidos pela organizaçă). }\end{array}$ \\
\hline 9 & $\begin{array}{l}\text { Elaboraçăa de documentaçăa externa da área (procedimentos } \\
\text { obrigatórios exigidos pela legislaçæo). }\end{array}$ \\
\hline 10 & $\begin{array}{l}\text { Controle de certificados de calibraçao e ensaios de equipamentos de } \\
\text { manutençăa. }\end{array}$ \\
\hline 11 & $\begin{array}{l}\text { Controle de horários, escalas e férias dos funcionários da área ( } 22 \\
\text { pessoas). }\end{array}$ \\
\hline 12 & $\begin{array}{l}\text { Acompanhamento, avaliaçao, mediçă dos serviços e interface com } \\
\text { terceirizados. }\end{array}$ \\
\hline 13 & Elaboraçăo de apresentaç১es técnicas e orçamentarias da área. \\
\hline
\end{tabular}

Fonte: Autores (2019)

Foram definidos os critérios de ranqueamento: tempo de execução e esforço empregado para mensurar o nível de esforço da tarefa, e os critérios: criticidade, gravidade, tendência, benefícios para a organização e impacto financeiro para mensurar o valor agregado de cada atividade. Sendo "criticidade" como o risco à saúde do trabalhador e terceiros, caso a tarefa não seja executada. Gravidade, o risco de danos à infraestrutura da organização e ao meio ambiente. Tendência, o potencial que o problema tem de crescer, caso a tarefa não seja realizada. Benefícios para a organização, todos os tipos de vantagem que a empresa pode obter com a execução da tarefa, que não financeiras. E impacto financeiro, o potencial do prejuízo financeiro que a empresa pode sofrer com a não execução da tarefa. Dessa forma, foram elencados 5 níveis para classificar cada critério. Em seguida, foi levantado junto ao líder do setor o peso que cada critério exerce na tomada de decisão, onde 0 é menos relevante e 2 é mais relevante.

O somatório dos pesos foi 8 , conforme apresentado na Tabela 4 a seguir. O campo total score da Tabela 5 representa a soma de todos os critérios e em seguida foi calculada a média ponderada para cada atividade. 
Tabela 5 - Critérios ranqueadores do valor agregado

\begin{tabular}{|c|c|c|c|c|c|c|c|}
\hline Pesos & 2 & 2 & 1,5 & 1 & 1,5 & 8 & \\
\hline Atividade & Criticidade & Gravidade & Tendência & $\begin{array}{c}\text { Benefícios Para } \\
\text { a Organização }\end{array}$ & $\begin{array}{l}\text { Impacto } \\
\text { Financeiro }\end{array}$ & $\begin{array}{l}\text { Total } \\
\text { Score }\end{array}$ & $\begin{array}{c}\text { Média } \\
\text { Ponderada }\end{array}$ \\
\hline 1 & 3 & 4 & 4 & 5 & 5 & 21 & 6,5 \\
\hline 2 & 5 & 5 & 5 & 5 & 5 & 25 & 8 \\
\hline 3 & 5 & 5 & 5 & 5 & 5 & 25 & 8 \\
\hline 4 & 1 & 2 & 3 & 3 & 4 & 13 & 3,9 \\
\hline 5 & 1 & 2 & 3 & 4 & 5 & 15 & 4,4 \\
\hline 6 & 1 & 3 & 4 & 4 & 4 & 16 & 4,8 \\
\hline 7 & 1 & 1 & 4 & 4 & 4 & 14 & 4 \\
\hline 8 & 3 & 1 & 2 & 23 & 1 & 30 & 7,1 \\
\hline 9 & 4 & 1 & 2 & 4 & 3 & 14 & 4,3 \\
\hline 10 & 4 & 1 & 2 & 3 & 2 & 12 & 3,8 \\
\hline 11 & 1 & 1 & 2 & 5 & 2 & 11 & 3 \\
\hline 12 & 1 & 1 & 2 & 2 & 3 & 9 & 2,7 \\
\hline 13 & 1 & 1 & 1 & 2 & 1 & 6 & 1,8 \\
\hline
\end{tabular}

Fonte: Autores (2019)

Na tabela 6 a seguir, pode-se observar que o mesmo foi feito para estimar os pesos, total score e média ponderada de cada atividade e, assim, determinarmos o nível de esforço empregado em cada uma delas.

Tabela 6 - Critérios ranqueadores do esforço

\begin{tabular}{|c|c|c|c|c|}
\hline Pesos & 1 & 2 & 3 & \multirow{2}{*}{} \\
\cline { 1 - 3 } Atividade & $\begin{array}{c}\text { Esforço } \\
\text { Empregado }\end{array}$ & $\begin{array}{c}\text { Tempo de } \\
\text { Execução }\end{array}$ & $\begin{array}{c}\text { Total } \\
\text { Score }\end{array}$ & $\begin{array}{c}\text { Média } \\
\text { Ponderada }\end{array}$ \\
\hline 1 & 1 & 3 & 4 & 3,5 \\
\hline 2 & 2 & 1 & 3 & 2 \\
\hline 3 & 1 & 2 & 3 & 2,5 \\
\hline 4 & 3 & 2 & 5 & 3,5 \\
\hline 5 & 3 & 3 & 6 & 4,5 \\
\hline 6 & 1 & 1 & 2 & 1,5 \\
\hline 7 & 2 & 1 & 3 & 2 \\
\hline 8 & 2 & 2 & 4 & 3 \\
\hline 9 & 2 & 2 & 4 & 3 \\
\hline 10 & 2 & 3 & 5 & 4 \\
\hline 11 & 3 & 4 & 7 & 5,5 \\
\hline 12 & 3 & 4 & 7 & 5,5 \\
\hline 13 & 4 & 2 & 6 & 4 \\
\hline
\end{tabular}

Fonte: Autores (2019)

Para elaborar a matriz de priorização, foi levado em consideração o resultado das médias ponderadas que cada critério exercia nas atividades, separados em dois tipos: Esforço e Valor Agregado. Em seguida, foi calculada a média aritmética entre os dois fatores e o resultado está elucidado na Tabela 7seguir: 
Tabela 7 - Resultados dos valores da matriz

\begin{tabular}{|c|c|c|c|}
\hline Atividades & Esforço & Valor Agregado & Média \\
\hline 1 & 3,5 & 6,5 & 5 \\
\hline 2 & 2 & 8 & 5 \\
\hline 3 & 2,5 & 8 & 5,25 \\
\hline 4 & 3,5 & 3,9 & 3,7 \\
\hline 5 & 4,5 & 4,4 & 4,45 \\
\hline 6 & 1,5 & 4,8 & 3,15 \\
\hline 7 & 2 & 4 & 3 \\
\hline 8 & 3 & 7,1 & 5,05 \\
\hline 9 & 3 & 4,3 & 3,65 \\
\hline 10 & 4 & 3,8 & 3,9 \\
\hline 11 & 5,5 & 3 & 4,25 \\
\hline 12 & 5,5 & 2,7 & 4,1 \\
\hline 13 & 4 & 1,8 & 2,9 \\
\hline
\end{tabular}

Fonte: Autores (2019)

Assim, foi possível gerar um gráfico de dispersão no software Excel onde as atividades são retratadas como bolhas e separadas por quadrantes de acordo com o nível de valor agregado e esforço consumido. Na Figura 5 a seguir, é possível observar que, no quadrante "I" se encontram as atividades que devem ser priorizadas, já que produzem alto valor à organização e consomem menos esforço.

Figura 5 - Matriz de priorização

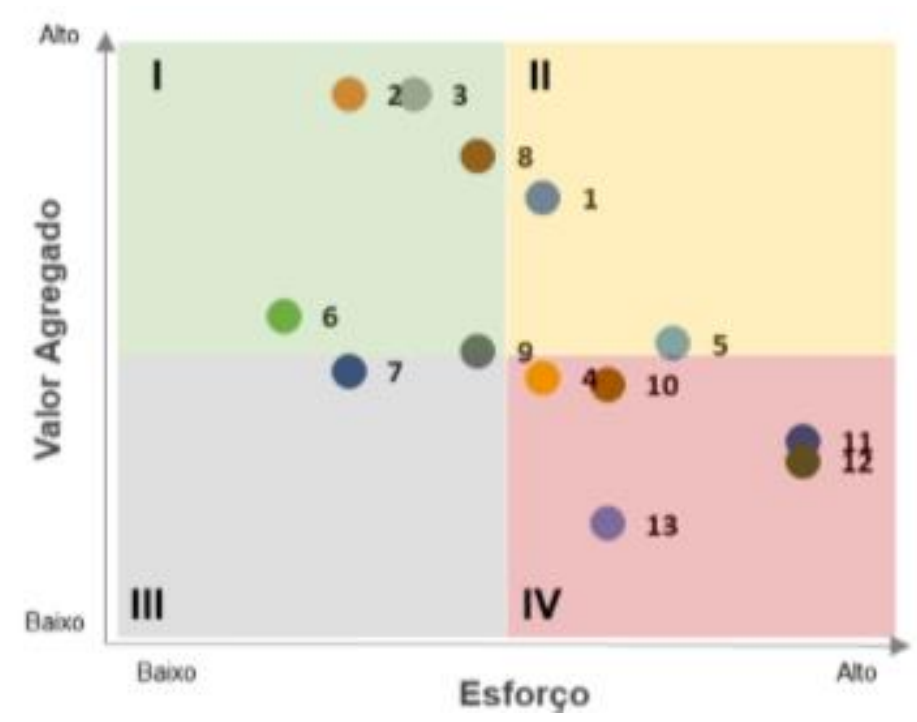

Fonte: Autores (2019)

Em contrapartida, as atividades que estão dispostas no "IV" quadrante requerem maior esforço em sua execução e geram pouco ou nenhum valor à organização. Estas devem ser 
deixadas em último plano, ou até mesmo eliminadas. Na Tabela 8 a seguir, foram listadas todas as atividades por ordem de priorização, onde as que apresentam maior valor de média se encontram no topo, enquanto que as atividades com menor média se encontram no final da tabela.

Tabela 8 - Visão das atividades por ordem de média

\begin{tabular}{|c|c|c|c|}
\hline Atividades & Esforço & Valor Agregado & Média \\
\hline 3 & 2,5 & 8 & 5,25 \\
\hline 8 & 3 & 7,1 & 5,05 \\
\hline 1 & 3,5 & 6,5 & 5 \\
\hline 2 & 2 & 8 & 5 \\
\hline 5 & 4,5 & 4,4 & 4,45 \\
\hline 11 & 5,5 & 3 & 4,25 \\
\hline 12 & 5,5 & 2,7 & 4,1 \\
\hline 10 & 4 & 3,8 & 3,9 \\
\hline 4 & 3,5 & 3,9 & 3,7 \\
\hline 9 & 3 & 4,3 & 3,65 \\
\hline 6 & 1,5 & 4,8 & 3,15 \\
\hline 7 & 2 & 4 & 3 \\
\hline 13 & 4 & 1,8 & 2,9 \\
\hline
\end{tabular}

Fonte: Autores (2019)

Na tabela 9 a seguir, porém, foi apresentada uma visão das atividades ordenadas a partir do nível de priorização, isto é, o seu posicionamento na matriz de priorização.

Tabela 8 - Visão das atividades por ordem de priorização

\begin{tabular}{|c|c|c|c|c|}
\hline Atividade & Esforço & Valor Agregado & Média & Quadrante \\
\hline 3 & 2,5 & 8 & 5,25 & \multirow{5}{*}{ I } \\
\hline 8 & 3 & 7,1 & 5,05 & \\
\hline 2 & 2 & 8 & 5 & \\
\hline 9 & 3 & 4,3 & 3,65 & \\
\hline 6 & 1,5 & 4,8 & 3,15 & \\
\hline 1 & 3,5 & 6,5 & 5 & \multirow{2}{*}{ ॥ } \\
\hline 5 & 4,5 & 4,4 & 4,45 & \\
\hline 7 & 2 & 4 & 3 & III \\
\hline 11 & 5,5 & 3 & 4,25 & \multirow{5}{*}{ IV } \\
\hline 12 & 5,5 & 2,7 & 4,1 & \\
\hline 10 & 4 & 3,8 & 3,9 & \\
\hline 4 & 3,5 & 3,9 & 3,7 & \\
\hline 13 & 4 & 1,8 & 2,9 & \\
\hline
\end{tabular}

Fonte: Autores (2019) 
Como pode ser observado, a atividade 1 apesar de ter um valor de média 5, se encontra no "II" quadrante, enquanto que a atividade 2 com mesmo valor se encontra no "I". Isso se dá, pois, a atividade 2 possui alto valor agregado e baixa necessidade de esforço para ser realizada. Já a atividade 1, é o oposto. Assim, é possível visualizar que, o que deve definir a priorização das atividades não é o seu valor de média apenas, mas sim o seu posicionamento na matriz de priorização.

\subsection{Análise do Processo de Cadastro de FIR (Formulários de Inspeção Rotineira)}

Após análises realizadas, foi proposto um novo modelo do processo de cadastro de FIR, utilizando a notação BPMN para melhor visualização e entendimento do processo futuro (To $\mathrm{Be}$ ), conforme pode-se observar na Figura 6 a seguir.

Figura 6: Mapeamento do processo de cadastro de FIR, fase atual ( $T o \mathrm{Be}$ )

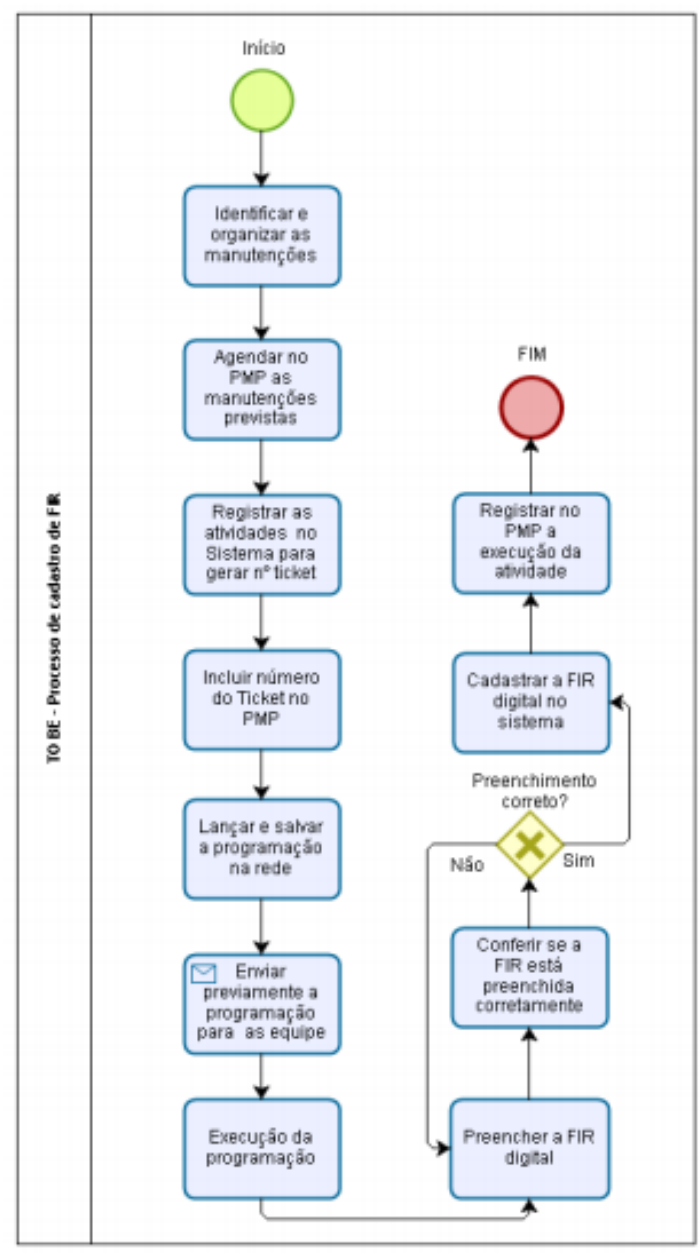

Fonte: Autores (2019) 


\section{Considerações Finais}

Foi possível mapear o processo atual $(A s I s)$ e sugerir melhorias para o processo futuro (To $B e$ ). Também foi possível analisar os dados coletados durante a verificação do problema, por meio do gráfico de Pareto e foi constatado que os FIR (Formulários de Inspeção Rotineira) com periodicidade mensal, bimestral e semestral equivalem a $80 \%$ das pendências e representam o gargalo da atividade principal do setor de manutenção. Em seguida, foi realizada a análise do tempo de ciclo e constatou-se que o maior impacto no tempo total de ciclo dava-se devido à atividade de impressão. Utilizando o Bizagi Modeler, foi possível criar o fluxograma do processo de cadastro de formulários de Inspeção Rotineira, onde foram removidas duas etapas do processo, em virtude do ganho de tempo na atividade.

Com a matriz de priorização foi possível identificar quais as tarefas que devem ser executadas em detrimento de outras que não agregam tanto valor e não justificam o esforço demandado, possibilitando, assim, o direcionamento adequado dos esforços. Assim, utilizando o Google Forms, a FIR impressa foi substituída pela FIR digital, o que reduziu em 52\% o tempo total do ciclo, além de economizar em média 792 folhas de papel por mês. Em vista disso, pode-se afirmar que houve redução de desperdício de tempo, de material e de movimentação.

Portanto, houve um ganho significativo em produtividade, já que com o método empregado foi possível realizar a mesma atividade investindo menos tempo e possibilitando a economia de dinheiro.

\section{REFERÊNCIAS}

BELMIRO, N. J.; Tecnologia da Informação Gerencial. São Paulo: Pearson Education do Brasil, 2015.

BIZAGI. Modelagem com Bizagi Process Modeler (Online). Disponível em:

<https://www.bizagi.com/en/modelagem-com-bizagi-process-modeler-online>. Acesso em 13 de set. 19.

GONÇALVES, L. C. V. O gerenciamento da fadiga de voo no âmbito da força aérea brasileira: uma nova abordagem. In: Revista científica de segurança e voo: Conexão SIPAER. 2011. Disponível em: < https://pdfs.semanticscholar.org/35a0/fc7e39afae04d2843e9042c010a2614b5 5eb.pdf>. Acesso em 28 out. 19.

GONÇALVES, Fabiano. Gestão de processos. 1. Ed. Rio de Janeiro: SESES, 2014.

GOOGLE. Formulários. Disponível em: <https://gsuite.google.com.br/intl/ptBR/products/forms/>. Acesso em 13 set. 19.

GRECO, Maria F. O. Agilização dos processos judiciais na comarca da capital: estudo de caso com aplicação de ferramentas da gestão pela qualidade total. 2005. 100 f. Dissertação (Pós-graduação em Administração Judiciária). 2005. 
MARANHÃO, M. O processo nosso de cada dia: modelagem de processos de trabalho. Rio de Janeiro: Qualitymark, 2004.

PAIM, Rafael; Cardoso, Vinicius; Carellinarex, Heitor; Clemente, Rafael. Gestão de Processos: Pensar, agir e aprender. Porto Alegre: Bookman, 2009.

PALADINI, Edson. Gestão da qualidade: teoria e prática. 2.ed. São Paulo: Atlas, 2009.

SELEME, Robson. Controle da qualidade: as ferramentas essenciais [livro eletrônico]. 2. Ed. Curitiba: Ibpex, 2012.

SLACK, Nigel; CHAMBERS, Stuart; JOHNSTON, Robert. Administração da produção. 3. ed. São Paulo: Atlas, 2009.

TÁLAMO, J. R. Engenharia de métodos: o estudo de tempos e movimentos. 1. Ed. Curitiba: Intersaberes, 2016.

WERKEMA, Cristina. Criando a cultura seis sigma. 3. Ed. [recurso eletrônico] - Rio de Janeiro: Elsevier, 2012.

Zabaleta, J.P.L. Matriz de priorização: uma ferramenta para estabelecer prioridades. 1. Ed. Pelotas: Embrapa Clima Temperado, 2002. 